\title{
ANALISIS MODEL KEGAGALAN KONSTRUKSI RUMAH TINGGAL 2 LANTAI AKIBAT RANGKAK DI BAWAH LERENG TIMBUNAN
}

\author{
Jeffri Ardianto ${ }^{1}$ dan Chaidir Anwar Makarim² \\ ${ }^{1}$ Program Studi Sarjana Teknik Sipil, Universitas Tarumanagara, Jl. Letjen S. Parman No.1 Jakarta \\ jeffri.325170052@stu.untar.ac.id \\ ${ }^{2}$ Program Studi Sarjana Teknik Sipil, Universitas Tarumanagara, Jl. Letjen S. Parman No.1 Jakarta \\ chaidir259@gmail.com
}

Masuk: 12-07-2021, revisi: 06-08-2021, diterima untuk diterbitkan: 19-08-2021

\begin{abstract}
Construction of houses on slopes certainly has risks that can cause landslides on the slopes. One of the construction projects on slope area experienced a construction failure which caused the destruction of a 2-storey house. It is suspected that the planning of the building did not take into account the optimal rainfall. The author makes a model analysis similar to that case using a shallow foundation. The subgrade in this case is soft soil from rice fields which is then backfilled with silty clay. The soft soil beneath this embankment experiences creep, where the soil continues to move slowly even without a load. The author analyzes the settlement due to creep manually. The author also analyzes the safety factor of slope stability due to rising ground water levels. Based on the calculation results, the settlement was obtained at 14,8456 cm which is almost close to the maximum settlement limit of $15 \mathrm{~cm}$. While the safety factor obtained from the application of the equilibrium limit before the rain is 1,311 but after experiencing a $5 \mathrm{~m}$ increase in ground water the safety factor is 1,032 which is less than 1,25.
\end{abstract}

Keywords: creep, settlement, shallow foundation, slope stability

\begin{abstract}
ABSTRAK
Pembangunan rumah di daerah lereng tentu memiliki risiko yang dapat menyebabkan kelongsoran pada daerah lereng. Salah satu proyek pembangunan pada suatu daerah lereng mengalami kegagalan konstruksi yang menyebabkan hancurnya rumah tinggal 2 lantai. Diduga dalam perencanaan bangunan tidak memperhitungkan curah hujan optimal. Penulis membuat analisis model yang mirip dengan kasus tersebut dengan menggunakan fondasi dangkal. Tanah dasar pada kasus ini adalah tanah lunak bekas persawahan yang kemudian di timbun dengan tanah lempung kelanauan. Tanah lunak di bawah tanah timbunan ini mengalami rangkak yang dimana tanah terus bergerak secara lambat walaupun tanpa adanya beban. Penulis menganalisis penurunan akibat dari rangkak secara manual. Penulis juga menganalisis faktor keamanan kestabilan lereng akibat dari naiknya muka air tanah. Berdasarkan hasil perhitungan, penurunan total terbesar diperoleh sebesar 14,8456 cm yang hampir mendekati batas penurunan maksimum $15 \mathrm{~cm}$. Sedangkan faktor keamanan yang diperoleh dari aplikasi kesetimbangan batas sebelum hujan sebesar 1,311 tetapi setelah mengalami kenaikan muka air tanah 5 m faktor keamanannya sebesar 1,187 yang dimana faktor keamanan kurang dari 1,25.
\end{abstract}

Kata kunci: rangkak, penurunan tanah, fondasi dangkal, kestabilan lereng

\section{PENDAHULUAN}

Pertumbuhan pendududuk di Indonesia sangat pesat, bahkan jumlah penduduk di Indonesia pada tahun 2021 ini mencapai 271 juta jiwa (Idris, 2021). Rumah tinggal merupakan kebutuhan pokok manusia yang harus dipenuhi. Maka tentunya dibutuhkan pembangunan rumah tinggal yang lebih luas lagi untuk memenuhi kebutuhan masyarakat. Hal ini mendorong banyak pihak untuk menyediakan sarana pemukiman untuk dapat ditinggali oleh masyarakat. Perumahan merupakan salah satu pembangunan yang sedang bekembang pesat di beberapa daerah. Dengan adanya pembangunan perumahan ini akan memudahkan orang mencari tempat untuk ditinggali.

Kebutuhan penduduk untuk mendapat tempat tinggal terus meningkat seiring dengan pertumbuhan jumlah penduduk yang terus bertambah, sedangkan persediaan lahan yang tersedia untuk pembangunan semakin terbatas. Seperti yang kita ketahui bahwa di Indonesia memiliki tanah dengan kondisi kontur yang bergelombang. Maka terdapat beberapa pembangunan di daerah-daerah tertentu dengan kondisi kontur tanah yang cukup ektrim. Contohnya pembangunan di daerah lereng tentu akan menimbulkan masalah geoteknik yang cukup serius, seperti masalah tanah longsor. Salah satu penyebab tanah longsor adalah erosi yang disebabkan aliran air permukaan atau air hujan. 
Kondisi tanah dasar yang kurang baik juga menjadi salah satu masalah dalam pembangunan proyek. Maka dari itu tanah tersebut butuh perlakuan khusus atau harus diolah terlebih dahulu sebelum membangun suatu proyek. Seperti tanah aluvial yang perlu diolah terlebih dahulu. Tanah Aluvial adalah tanah yang dibentuk dari lumpur sungai yang mengendap di dataran rendah yang memiliki sifat tanah yang subur dan cocok untuk lahan pertanian. (Soepratohardjo, 1976).

Identifikasi masalah dalam penelitian ini mengenai analisis model kegagalan konstruksi rumah tinggal 2 lantai akibat rangkak di bawah lereng timbunan.

Adapun batasan masalah dalam penelitian ini sebagai berikut:

1. Lokasi penelitian di suatu daerah Sumatera selatan.

2. Lokasi bangunan berada di tepi lereng.

3. Tidak memperhitungkan biaya (cost).

4. Beban gempa tidak diperhitungkan.

5. Data tanah yang digunakan merupakan data asumsi pendekatan kasus nyata.

Berikut rumusan masalah dalam penelitian ini:

1. Berapa besar penurunan tanah yang terjadi akibat dari rangkak di bawah tanah timbunan?

2. Berapa nilai faktor keamanan kestabilan lereng akibat dari hujan yang berlangsung lama sehingga mengakibatkan kenaikan muka air tanah?

Berikut tujuan dari penelitian ini:

1. Mengetahui penurunan tanah yang terjadi akibat dari rangkak.

2. Mengetahui nilai faktor keamanan kestabilan lereng setelah kenaikan muka air tanah.

\section{Tanah lunak}

Secara umum tanah lunak memiliki karakteristik sebagai berikut: daya dukung tanah terhadap beban yang sangat rendah, kuat geser yang rendah, bersifat plastis saat basah, mengembang, dapat dimampatkan sampai 35\% volume dan nilai standar penetrasi test $N$-value $<4$ dapat dikelompokkan sebagai tanah lunak.

Tanah lunak memiliki daya dukung tanah yang kecil, waktu konsolidasi yang lama dan pemampatan yang besar (Das, 1998). Tanah lunak dalam konstruksi dapat menjadi permasalahan. Daya dukung yang rendah akan menyebabkan kerugian, mulai dari kerugian dari sisi biaya konstruksi yang akan semakin mahal hingga angka keamanan yang rendah, sehingga menyebabkan ancaman terhadap keselamatan konstruksi. Struktur yang dibuat tidak dapat berdiri secara stabil dan bahkan berpotensi roboh (Putra \& Makarim, 2020).

\section{Rangkak}

Ciri-ciri rangkak di lapangan dapat menjadi indikasi jenis gerakan massa ini antara lain yaitu dari miringnya pohon dan tiang listrik. Di dekat permukaan tanah miring, tanah dipengaruhi oleh siklus kembang susut yang terjadi. Siklus ini dapat terjadi dikarenakan perubahan temperatur, perubahan dari musim kemarau ke musim hujan, dan di daerah dingin dapat disebabkan oleh efek pembekuan air. Ketika tanah mengembang, tanah naik sehingga melawan gaya gravitasi dan ketika tanah menyusut, tanah turun dengan bantuan gaya gravitasi. Kemudian hasil dari gerakan kedua tersebut adalah gerakan lereng turun ke arah bawah secara perlahan.

\section{Stabilitas lereng}

Menurut Margaretha, Turangan, \& Sompie (2014) gerakan tanah terjadi karena adanya gangguan kestabilan tanah atau batuan penyusun lereng, sehingga terjadi gerakan yang menuruni lereng oleh massa tanah dan bantuan penyusun lereng tersebut. Dari definisi di atas menyatakan bahwa massa yang bergerak dapat berupa massa tanah, massa batuan atau pencampuran antara massa tanah dan batuan penyusun lereng. Jika massa yang bergerak ini didominasi oleh massa tanah dan bergerak melalui suatu bidang berupa lereng ataupun lengkung pada suatu lereng, maka proses gerakan ini dapat disebut sebagai longsoran tanah. Analisis stabilitas tanah di permukaan tanah ini yaitu analisis stabilitas lereng. Faktor keamanan lereng dibagi menjadi 3 kelompok ditinjau dari intensitas kelongsoran yang terjadi (Bowles, 1989) seperti pada Tabel 1. 
Tabel 1. Hubungan faktor keamanan lereng dan intensitas longsor

\begin{tabular}{cc}
\hline Nilai faktor keamanan & Kejadian/intensitas longsor \\
\hline$<1,07$ & Longsor biasa/sering terjadi (lereng labil) \\
$1,07<\mathrm{SF}<1,25$ & Longsor pernah terjadi (lereng kritis) \\
$>1,25$ & Longsor jarang terjadi (lereng relatif stabil) \\
\hline
\end{tabular}

(Sumber: Bowles,1989)

Akibat gaya dari luar yang bekerja pada material pembentuk lereng akan menyebabkan material pembentuk lereng memiliki kecenderungan untuk menggelincir. Kekuatan geser material itu sendiri dapat menahan kecenderungan menggelincir ini. Walaupun lereng tersebut telah stabil dalam waktu yang lama, memungkinkan lereng tersebut dapat menjadi tidak stabil karena adanya beberapa faktor seperti:

1. Jenis dan keadaan lapisan tanah atau batuan pembentuk lereng.

2. Bentuk geometris penampang lereng (seperti tinggi dan kemiringan pada lereng).

3. Peningkatan kadar air pada tanah (seperti rembesan air maupun infiltrasi hujan).

4. Gempa atau getaran.

5. Berat dan distribusi beban.

\section{Daya dukung fondasi dangkal}

Umumnya perhitungan kapasitas daya dukung didasarkan pada analisis-analisis keruntuhan geser lokal dan keruntuhan penetrasi, nilai kapasitas dukung ijin $\left(\mathrm{q}_{\mathrm{u}}\right)$ dapat ditentukan dari pertimbangan besar penurunanya. Untuk nilai daya dukung ijin digunakan faktor keamanan sebesar 3 berdasarkan dari SNI 8460. Sedangkan untuk perhitungan daya dukung fondasi dangkal dapat dihitung dengan beberapa metode yaitu:

1. Metode Terzaghi

Terzaghi memberikan koreksi empiris dalam faktor-faktor kapasitas dukung pada saat kondisi keruntuhan geser umum, yang digunakan untuk perhitungan kapasitas dukung pada kondisi keruntuhan geser lokal. Nilai-nilai $\mathrm{N}_{\gamma}, \mathrm{N}_{\mathrm{c}}, \mathrm{N}_{\mathrm{q}}$ merupakan faktor-faktor kapasitas dukung tanah yang adalah fungsi dari sudut gesek pada $(\phi)$ tanah berdasarkan Terzaghi \& Peck (1943).

Persamaan umum kapasitas dukung Terzaghi dapat dituliskan sebagai berikut:

$$
q_{u}=c \cdot N_{c} \cdot S_{c}+\bar{q} \cdot N_{q}+0,5 \cdot \gamma \cdot \mathrm{B} \cdot \mathrm{N}_{\gamma} \cdot \mathrm{s}_{\gamma}
$$

dengan $\mathrm{q}_{\mathrm{u}}=$ daya dukung ultimit, $\mathrm{c}=$ kohesi tanah, $\gamma=$ berat jenis tanah dan $\mathrm{N}_{\gamma}, \mathrm{N}_{\mathrm{c}}, \mathrm{N}_{\mathrm{q}}=$ faktor daya dukung Terzaghi.

Untuk bentuk fondasi memanjang, Terzaghi \& Peck (1943) dalam Das (2004) dampak faktor dari bentuk fondasi terhadap daya dukung ultimit dalam analisis fondasi memanjang, sebagai berikut:

- $\quad$ Fondasi bujur sangkar

$$
q_{u}=1,3 \cdot c \cdot N_{c}+\bar{q} \cdot N_{q}+0,4 \cdot \gamma \cdot \mathrm{B} \cdot \mathrm{N}_{\gamma}
$$

- $\quad$ Fondasi lingkaran

$$
q_{u}=1,3 \cdot c \cdot N_{c}+\bar{q} \cdot N_{q}+0,3 \cdot \gamma \cdot \mathrm{B} \cdot \mathrm{N}_{\gamma}
$$

- $\quad$ Fondasi empat persegi panjang

$$
q_{u}=c \cdot N_{c}\left(1+\frac{0,3 B}{L}\right)+\bar{q} \cdot N_{q}+0,5 \cdot \gamma \cdot \mathrm{B} \cdot \mathrm{N}_{\gamma}\left(1-\frac{0,2 B}{L}\right)
$$

dengan $\mathrm{q}_{\mathrm{u}}=$ daya dukung ultimit, $\mathrm{c}=$ kohesi tanah, $\gamma=$ berat jenis tanah dan $\mathrm{N}_{\gamma}, \mathrm{N}_{\mathrm{c}}, \mathrm{N}_{\mathrm{q}}=$ faktor daya dukung Terzaghi.

2. Metode Meyerhof

Meyerhof (1951) dalam Bowles (1992) menyarankan bahwa persamaan daya dukung yang mirip dengan rumus daya dukung metode Terzaghi namun memasukkan suatu faktor bentuk $\mathrm{s}_{\mathrm{q}}$, faktor kedalaman $\mathrm{d}_{\gamma}$ dan faktor kemiringan $\mathrm{i}_{\gamma}$. Persamaaan kapasitas daya dukung metode Meyerhof dapat dituliskan sebagai berikut:

- Beban vertikal

$$
q_{u}=c \cdot N_{c} \cdot S_{c} \cdot d_{c}+\bar{q} \cdot N_{q} \cdot s_{q} \cdot d_{q}+0,5 \cdot \gamma \cdot \mathrm{B} \cdot \mathrm{N}_{\gamma} \cdot s_{\gamma} \cdot \mathrm{d}_{\gamma}
$$


- $\quad$ Beban miring

$$
q_{u}=c \cdot N_{c} \cdot S_{c} \cdot i_{c}+\bar{q} \cdot N_{q} \cdot s_{q} \cdot i_{q}+0,5 \cdot \gamma \cdot \mathrm{B} \cdot \mathrm{N}_{\gamma} \cdot \mathrm{d}_{\gamma} \cdot \mathrm{i}_{\gamma}
$$

dengan $\mathrm{q}_{\mathrm{u}}=$ daya dukung ultimit, $\mathrm{c}=$ kohesi tanah, $\gamma=$ berat jenis tanah, $\mathrm{N}_{\gamma}, \mathrm{N}_{\mathrm{c}}, \mathrm{N}_{\mathrm{q}}=$ faktor daya dukung Meyerhof, $\mathrm{s}_{\mathrm{q}}=$ faktor bentuk, $\mathrm{d}_{\gamma}=$ faktor kedalaman dan $\mathrm{i}_{\gamma}=$ faktor kemiringan.

3. Metode Hansen

Hansen (1970) dalam Bowles (1992) menyarankan bahwa persamaan daya dukung fondasi dapat digunakan sebagai berikut:

$$
q_{u}=c N_{c} S_{c} s_{c} d_{c} i_{c} g_{c} b_{c}+\bar{q} N_{q} s_{q} d_{q} i_{q} g_{q} b_{q}+0,5 \gamma B N_{\gamma} s_{\gamma} \mathrm{d}_{\gamma} \mathrm{i}_{\gamma} \mathrm{g}_{\gamma} \mathrm{b}_{\gamma}
$$

Jika, $\phi=0^{\circ}$

$$
q_{u}=5,14 S_{u}\left(1+s_{c}^{\prime}+d_{c}^{\prime}-i_{c}^{\prime}-b_{c}^{\prime}-g^{\prime}{ }_{c}\right)+q
$$

dengan $\mathrm{q}_{\mathrm{u}}=$ daya dukung ultimit, $\mathrm{c}=$ kohesi tanah, $\gamma=$ berat jenis tanah, $\mathrm{N}_{\gamma}, \mathrm{N}_{\mathrm{c}}, \mathrm{N}_{\mathrm{q}}=$ faktor daya dukung Hansen, $\mathrm{s}_{\mathrm{q}}=$ faktor bentuk, $\mathrm{d}_{\gamma}=$ faktor kedalaman dan $\mathrm{i}_{\gamma}=$ faktor kemiringan.

4. N-SPT

Untuk daya dukung dari data N-SPT dapat digunakan persamaan daya dukung fondasi sebagai berikut:

$$
q_{u}=\frac{N \prime 70}{F_{2}}\left(B+\frac{F_{3}}{B}\right)^{2} k d
$$

dengan $\mathrm{q}_{\mathrm{u}}=$ daya dukung ultimit dan $\mathrm{B}=$ lebar fondasi.

\section{Penurunan tanah}

Penurunan (settlement) merupakan istilah yang digunakan untuk menunjukkan pergerakan suatu titik tertentu pada bangunan terhadap titik acuan yang tetap. Penurunan (settlement) fondasi pada tanah berbutir halus yang jenuh dapat dibagi menjadi 3 komponen, yaitu: penurunan segera (immediate settlement), penurunan konsolidasi primer, dan penurunan konsolidasi sekunder. Penurunan total merupakan jumlah dari ketiga komponen penurunan tersebut, atau jika dinyatakan dalam persamaan yaitu:

$$
\mathrm{S}_{\mathrm{t}}=\mathrm{S}_{\mathrm{i}}+\mathrm{S}_{\mathrm{c}}+\mathrm{S}_{\mathrm{s}}
$$

dengan $\mathrm{S}_{\mathrm{t}}=$ penurunan total, $\mathrm{S}_{\mathrm{i}}=$ penurunan segera, $\mathrm{S}_{\mathrm{c}}=$ penurunan konsolidasi primer dan $\mathrm{S}_{\mathrm{s}}=$ penurunan konsolidasi sekunder.

\section{Penurunan segera}

Penurunan segera (immediate settlement) dari suatu fondasi terjadi dengan segera setelah beban diberikan tanpa menyebabkan terjadinya perubahan kadar air. Besarnya penurunan segera ini akan bergantung pada kondisi dari fondasi dan jenis dari material di mana fondasi tersebut berada (Das, 1995). Pada tanah yang permeabilitas tinggi, tegangan air pori yang terjadi hanya sebentar, hal ini disebabkan karena tegangan air pori ini menghilang dengan cepat. Persamaan besarnya penurunan segera (Janbu, Bjerrum, \& Kjalrnsli, 1956) sebagai berikut:

$$
S_{i}=\mu_{1} \cdot \mu_{0} \cdot \frac{q B}{E}
$$

dengan $\mathrm{S}_{\mathrm{i}}=$ penurunan segera, $\mu_{1}=$ koefisien (perbandingan antara $\mathrm{H}$ dan $\mathrm{B}$ ), $\mu_{0}=$ koefisien (perbandingan antara $\mathrm{D}$ dan $\mathrm{B}$ ), $\mathrm{q}=$ tegangan pada bidang kontak antara beban dan tanah dasar, $\mathrm{B}=$ lebar timbunan ekivalen dan $\mathrm{E}=$ modulus young.

\section{Penurunan konsolidasi primer}

Jika tanah lempung jenuh tiba-tiba terendam dengan air, maka tekanan pada tanah akibat beban tersebut tidak hanya mengakibatkan kompresi elastis penurunan segera, tetapi juga menyebabkan tekanan air pori yang berlebihan. Jika air meninggalkan rongga pori lapisan tanah tertekan, maka tekanan air pori dapat berkurang. Ketika volume air di dalam rongga pori berkurang, hal tersebut dapat mengakibatkan pengurangan volume tanah. Karena permeabilitas lempung rendah, maka perubahan volume yang terjadi berlangsung lama dan merupakan fungsi dari waktu. Tanah yang sedang mengalami proses demikian disebut dengan sedang berkonsolidasi, dan perubahan volume dalam arah vertikal disebut penurunan konsolidasi primer. 
Besarnya penurunan konsolidasi primer untuk lempung yang terkonsolidasi secara normal (normally consolidated) dapat dihitung dengan menggunakan persamaan sebagai berikut:

$$
S_{c}=\frac{C_{S} H}{1+e_{0}} \log \left(\frac{\sigma_{0^{\prime}+\Delta \sigma}}{\sigma_{0^{\prime}}}\right)
$$

Sedangkan untuk lempung yang terlalu terkonsolidasi (overconsolidated), besarnya penurunan dihitung dengan menggunakan persamaan sebagai berikut:

Jika $\sigma_{0}^{\prime}+\Delta \sigma \leq \sigma_{c}$, maka:

$$
S_{c}=\frac{C_{S} H}{1+e_{0}} \log \left(\frac{\sigma_{0^{\prime}+\Delta \sigma}}{\sigma_{0^{\prime}}}\right)
$$

Jika $\sigma_{0}^{\prime}+\Delta \sigma>\sigma_{c}$, maka:

$$
S_{C}=\frac{C_{s} \cdot H}{1+e_{0}} \log \left(\frac{\sigma_{c^{\prime}}}{\sigma_{0^{\prime}}}\right)+\frac{C_{c^{\prime}} \cdot H}{1+e_{0}} \log \left(\frac{\sigma_{0}^{\prime}+\Delta \sigma}{\sigma_{c}}\right)
$$

dengan $\mathrm{S}_{\mathrm{c}}=$ penurunan konsolidasi primer, $\mathrm{C}_{\mathrm{c}}=$ indeks pemampatan, $\mathrm{C}_{\mathrm{s}}=$ indeks pemuaian, $\mathrm{e}_{0}=$ void ratio awal, $\mathrm{H}$ $=$ tinggi tanah terkonsolidasi, $\sigma_{0}{ }^{\prime}=$ tegangan overburden efektif, $\sigma_{\mathrm{c}}{ }^{\prime}=$ tegangan prakonsolidasi efektif dan $\Delta \sigma=$ penambahan tegangan.

\section{Penurunan konsolidasi sekunder}

Penurunan konsolidasi sekunder terjadi pada tegangan efektif konstan, yaitu dimana setelah penurunan konsolidasi primer berhenti. Besar penurunannya merupakan fungsi waktu (t) dan kemiringan kurva indeks pemampatan sekunder $\left(C_{\propto}\right)$. Kemiringan $C_{\propto}$ dinyatakan dalam persamaan berikut:

$$
C_{\propto}=\frac{\Delta e}{\log \left(\frac{t 2}{t 1}\right)}
$$

Rasio pemampatan sekunder (secondary compression index), $C_{\propto \varepsilon}$ dinyatakan oleh:

$$
C_{\propto \varepsilon}=C_{\propto} /\left(1+e_{p}\right)
$$

Penurunan konsolidasi sekunder, dihitung dengan persamaan berikut:

$$
S_{\mathrm{s}}=\frac{C_{\propto}}{1+e \mathrm{p}} H \log \frac{t_{2}}{t_{1}}
$$

Atau,

$$
S_{\mathrm{s}}=C_{\propto} H \log \frac{t_{2}}{t_{1}}
$$

dengan $\mathrm{S}_{\mathrm{s}}=$ penurunan konsolidasi sekunder, $\mathrm{H}=$ tebal benda uji awal, $\mathrm{e}_{\mathrm{p}}=$ angka pori saat akhir konsolidasi primer, $\mathrm{t}_{2}=\mathrm{t}_{1}+\Delta \mathrm{t}$ dan $\mathrm{t}_{1}=$ saat waktu setelah konsolidasi primer berhenti.

Selama terjadinya konsolidasi sekunder, terdapat dua faktor yang dapat mempengaruhi prosesnya. Pertama adalah pengurangan volume tanah pada tegangan efektif konstan. Dan kedua adalah regangan vertikal yang disebabkan oleh gerakan tanah secara lateral di bawah struktur.

\section{Waktu penurunan konsolidasi}

Hal yang mempengaruhi waktu penurunan adalah panjangnya lintasan yang dilalui air pori untuk terdisipasi. Pada tanah, aliran disipasi air pori berlebih biasanya terjadi pada arah vertikal (Putra \& Makarim, 2020). Perbandingan antara pemampatan tanah pada saat t dengan pemampatan total yang tejadi disebut derajat konsolidasi.

Untuk derajat Konsolidasi 0-60\% dirumuskan dengan:

$$
U=\left(2 \sqrt{\frac{T_{v}}{\pi}}\right) 100 \%
$$


Untuk derajat Konsolidasi >60\% dirumuskan dengan:

$$
U=(100-a) \%
$$

dengan $\mathrm{U}=$ derajat konsolidasi, $\mathrm{T}_{\mathrm{v}}=$ faktor waktu dan $a=10^{\left(\frac{1.781-T}{0.933}\right)}$.

\section{Kecepatan Penurunan Konsolidasi}

Secara umum diperlukan estimasi kecepatan penurunan konsolidasi untuk menentukan besarnya kecepatan penurunan fondasi selama proses konsolidasi berlangsung. Hal ini perlu diperhatikan terutama jika penurunan yang terjadi diperkirakan cukup besar. Jika penurunan bangunan sangat kecil, tidak perlu mempertimbangkan kecepatan penurunan yang terjadi, hal ini disebabkan karena penurunan tidak akan membuat perbedaan yang berarti. Untuk menghitung penurunan konsolidasi pada waktu tertentu (t) digunakan persamaan sebagai berikut:

$$
t=\frac{T_{v} H_{t}^{2}}{C_{v}}
$$

dengan $T_{v}$ = faktor waktu, $H_{t}=$ panjang lintasan drainase $\left(H_{1}=H / 2\right.$, untuk drainase doubel dan $H_{1}=H$, untuk drainase tunggal) dan $\mathrm{C}_{\mathrm{v}}=$ koefisien konsolidasi pada interval tekanan tertentu.

\section{METODE PENELITIAN}

\section{Pengumpulan data}

Untuk melakukan analisis ini, data tanah yang dibutuhkan adalah data borlog dan data laboratorium. Serta dibutuhkannya juga data arsitektur bangunan rumah tinggal 2 lantai dan data curah hujan.

\section{Pengolahan data}

Studi Pustaka merupakan hal yang terlebih dahulu dicari sebelum melakukan pengolahan data. Studi Pustaka dilakukan bertujuan agar dapat mengetahui teori-teori yang membantu dalam pekerjaan penulisan penelitian ini. Setelah studi pustaka selesai, dilanjutkan dengan pengolahan data-data yang telah dikumpulkan. Data-data akan dipakai untuk melakukan analisis sebagai berikut:

1. Nilai N-SPT

2. Data borlog

3. Data Laboratorium

\section{Metode analisis data}

Analisis data akan dilakukan dengan cara menghitung penurunan tanah yang terjadi akibat dari rangkak secara manual serta mengecek faktor keamanan kestabilan lereng yang mengakibatkan keruntuhan bangunan menggunakan aplikasi kesetimbangan batas dengan metode bishop.

\section{Diagram alir penelitian}

Gambar diagram alir penelitian ditunjukan pada Gambar 1. 


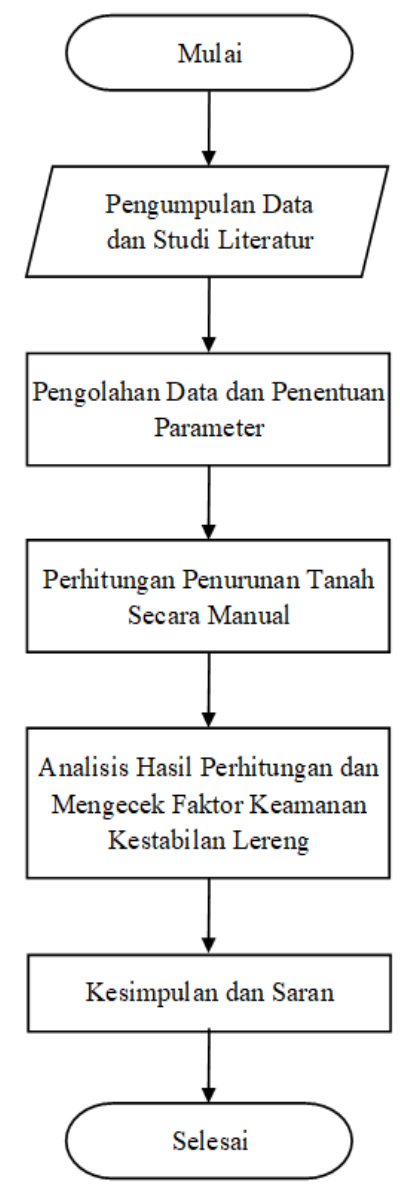

Gambar 1. Diagram alir penelitian

\section{HASIL DAN PEMBAHASAN}

Berdasarkan hasil perhitungan dan korelasi yang dilakukan, summary data tanah yang digunakan pada penelitian disajikan pada Tabel 2.

Tabel 2. Summary data tanah

\begin{tabular}{ccccccccccc}
\hline $\begin{array}{c}\text { Depth } \\
(\mathrm{m})\end{array}$ & $\begin{array}{c}\text { Type of } \\
\text { soil }\end{array}$ & $\begin{array}{c}\mathrm{N}- \\
\mathrm{SPT}\end{array}$ & $\begin{array}{c}\gamma_{\mathrm{sat}} \\
\left(\mathrm{kN} / \mathrm{m}^{3}\right)\end{array}$ & $\phi^{\prime}$ & $\begin{array}{c}\text { Su } \\
(\mathrm{kPa})\end{array}$ & $\begin{array}{c}\mathrm{Eu} \\
(\mathrm{MPa})\end{array}$ & $\begin{array}{c}\mathrm{c}^{\prime} \\
(\mathrm{kPa})\end{array}$ & Cc & Cs & Ca \\
\hline $0-4$ & Clayey silt & 6 & 18 & 25 & 36 & 10,8 & 7,2 & 0,13 & 0,090 & 0,0078 \\
$4-7$ & Silty clay & 3 & 17 & 25 & 18 & 5,4 & 3,6 & 0,13 & 0,090 & 0,0078 \\
$7-9$ & Silty clay & 2 & 17 & 25 & 12 & 3,6 & 2,4 & 0,13 & 0,090 & 0,0078 \\
$9-14$ & Sandy silt & 3 & 19 & 28 & 18 & 5,4 & 3,6 & 0,141 & 0,091 & 0,0084 \\
$14-18$ & Sand & 20 & 20 & 30 & - & - & - & - & - & - \\
$18-28$ & Clayey silt & 30 & 19 & 29 & 180 & 54 & 36 & 0,14 & 0,07 & 0,0084 \\
$28-31$ & Sandy silt & 53 & 20 & 30 & 318 & 95,4 & 63,6 & 0,1 & 0,05 & 0,006 \\
\hline
\end{tabular}

Bangunan yang akan digunakan untuk analiasis berupa rumah tinggal 2 lantai dengan jenis fondasi yang digunakan yaitu fondasi telapak disajikan pada Gambar 2 dan Gambar 3. 

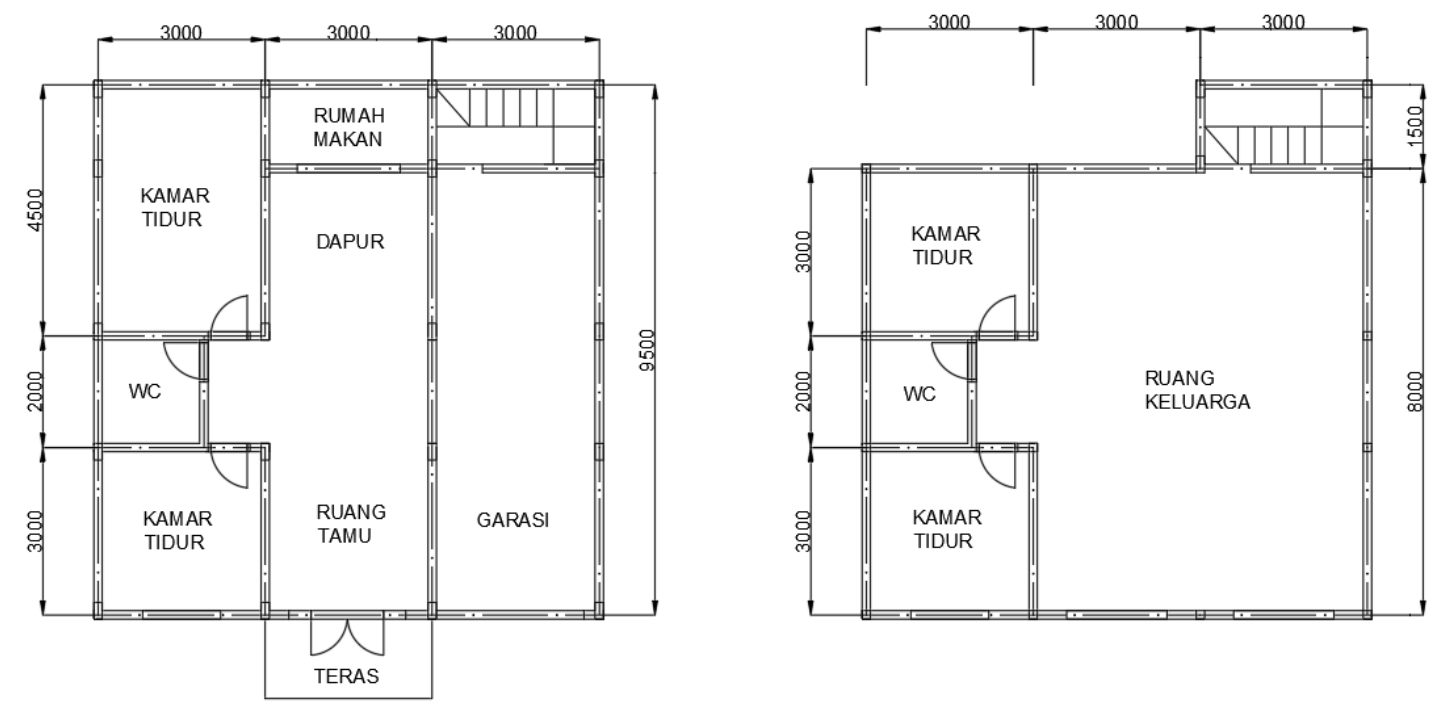

Gambar 2. Denah rumah lantai 1 (kiri) dan lantai 2 (kanan)

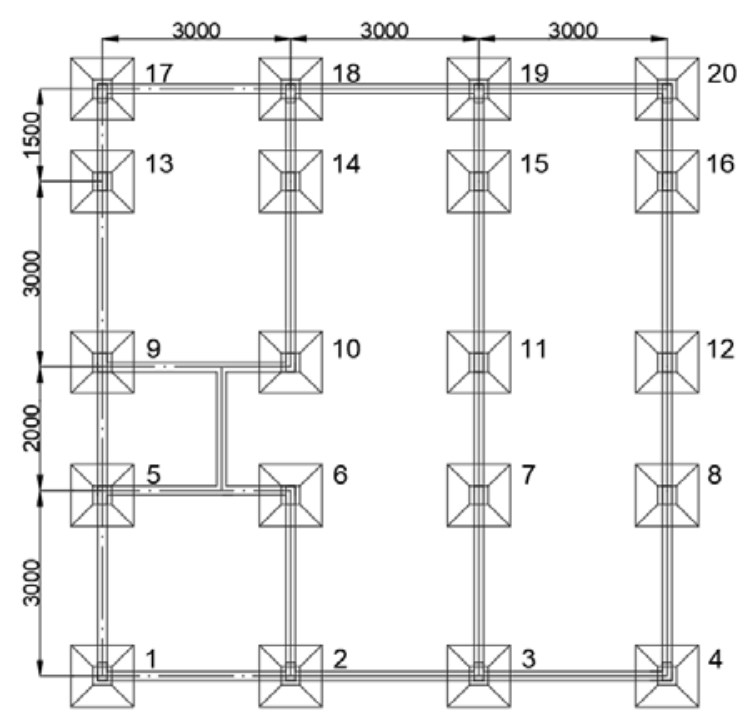

Gambar 3. Denah fondasi telapak

Bangunan ini berada pada 4 meter dari tepi lereng dengan kemiringan lereng sebesar $30^{\circ}$ seperti sketsa pada Gambar 4.

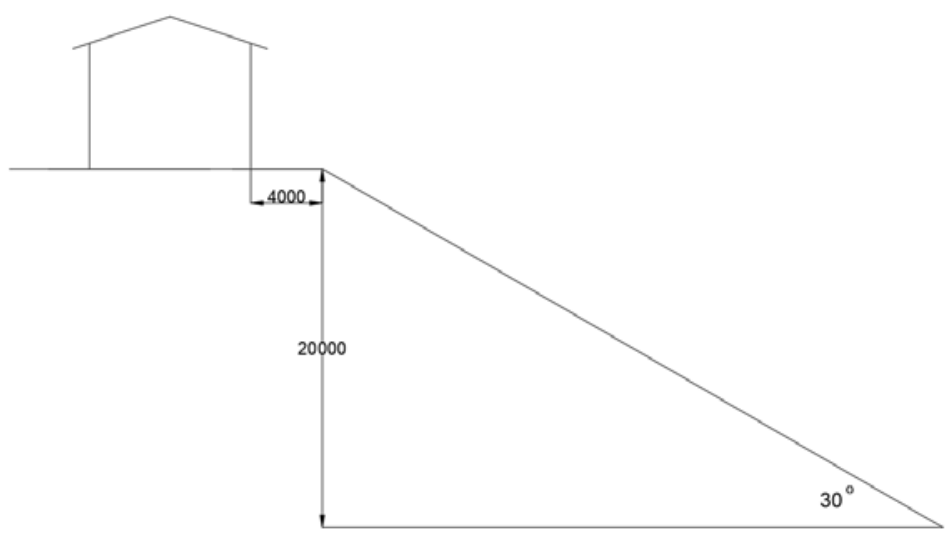

Gambar 4. Sketsa Lereng 
Data curah hujan bertambah pada bulan januari 2021 yang dimana terjadinya hujan yang berlangsung lama disajikan pada Tabel 3.

Tabel 3. Curah hujan januari 2021

\begin{tabular}{|c|c|}
\hline Tanggal & $\mathrm{RR}$ \\
\hline 01-01-2021 & 0,8 \\
\hline 02-01-2021 & 13,9 \\
\hline 03-01-2021 & 38,5 \\
\hline 04-01-2021 & 82,8 \\
\hline 05-01-2021 & 3,8 \\
\hline 06-01-2021 & 49,2 \\
\hline 07-01-2021 & 41,6 \\
\hline 08-01-2021 & 136,2 \\
\hline 09-01-2021 & 16,9 \\
\hline 10-01-2021 & 4,7 \\
\hline 11-01-2021 & 15 \\
\hline 12-01-2021 & 7,6 \\
\hline 13-01-2021 & 15,1 \\
\hline 14-01-2021 & 12,8 \\
\hline 15-01-2021 & 4,5 \\
\hline 16-01-2021 & 141,1 \\
\hline 17-01-2021 & 40,9 \\
\hline 18-01-2021 & 22,5 \\
\hline 19-01-2021 & 24,9 \\
\hline 20-01-2021 & 0,2 \\
\hline 21-01-2021 & 55,2 \\
\hline 22-01-2021 & 5,3 \\
\hline 23-01-2021 & 25,7 \\
\hline 24-01-2021 & 11 \\
\hline 25-01-2021 & 0,6 \\
\hline 26-01-2021 & 11,5 \\
\hline 27-01-2021 & 46 \\
\hline 28-01-2021 & 0,2 \\
\hline 29-01-2021 & - \\
\hline 30-01-2021 & 13,6 \\
\hline 31-01-2021 & 14,8 \\
\hline
\end{tabular}

Kemudian denah rumah dibuat model menggunakan aplikasi MIDAS seperti pada Gambar 5 yang lalu ditambah dengan beban dari bangunan itu sendiri. Hasil dari aplikasi ini berupa gaya-gaya yang diterima pada tiap kolom disajikan pada Tabel 4. Dimana titik kolom nomor 14 menerima gaya yang paling besar yaitu sebesar 151,3339 kN yang kemudian menjadi acuan untuk perhitungan daya dukung fondasi. 


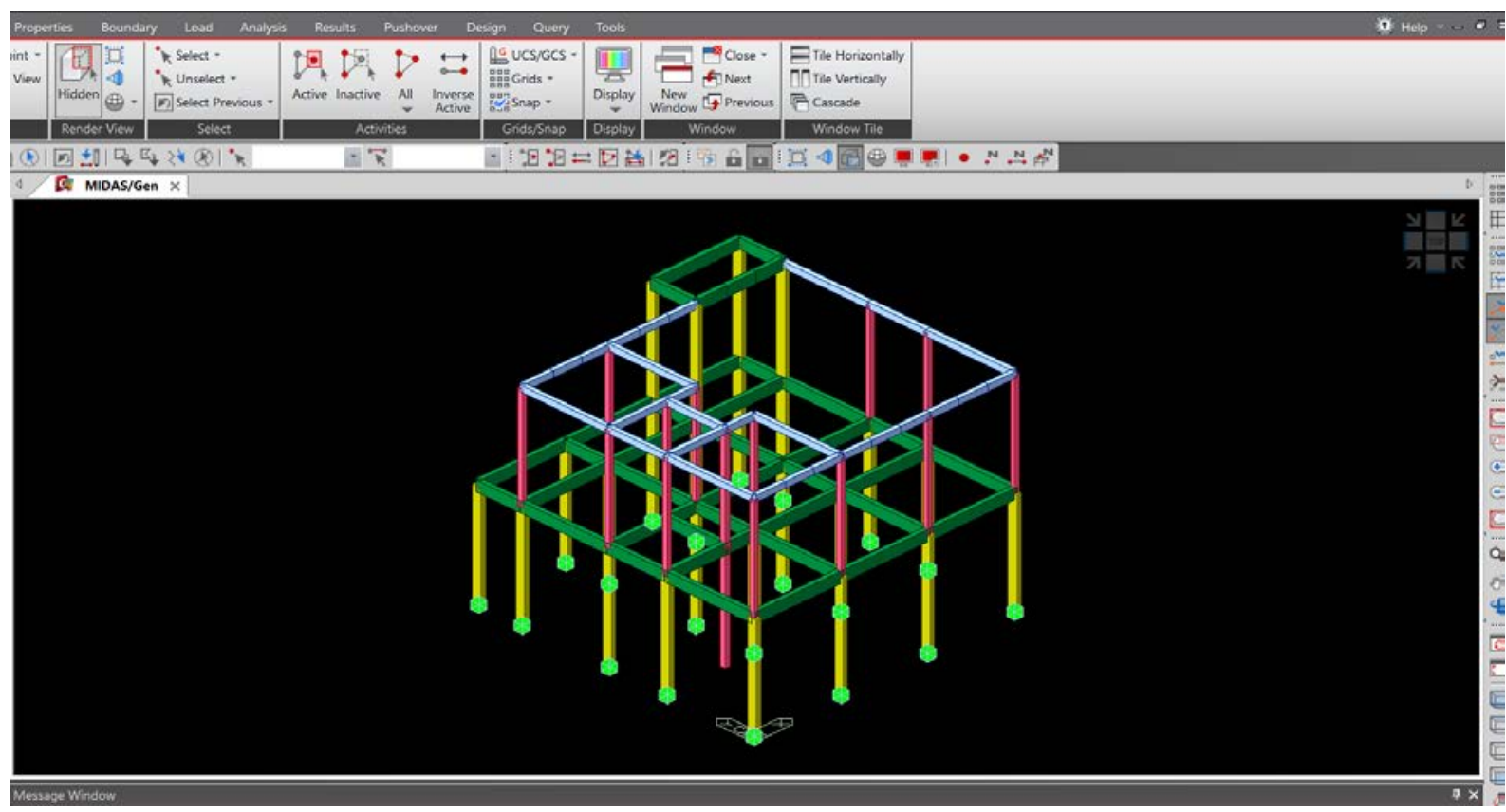

Gambar 5. Model struktur bangunan pada aplikasi MIDAS

Tabel 4. Hasil gaya kolom pada aplikasi MIDAS

\begin{tabular}{ccccccc}
\hline Titik & FX $(\mathrm{kN})$ & FY $(\mathrm{kN})$ & FZ $(\mathrm{kN})$ & MX $(\mathrm{kNm})$ & MY $(\mathrm{kNm})$ & $\mathrm{MZ}(\mathrm{kNm})$ \\
\hline 1 & 2,6107 & 2,8845 & 85,3027 & $-2,6793$ & 3,9528 & $-0,1889$ \\
2 & 1,0171 & 3,9736 & 137,6238 & $-4,0384$ & 2,0647 & $-0,0744$ \\
3 & 1,7000 & 2,8533 & 101,3082 & $-2,9855$ & 2,8604 & 0,0170 \\
4 & $-0,1214$ & 4,0785 & 68,6749 & $-5,3116$ & 0,8997 & $-0,0644$ \\
5 & 3,7037 & $-2,5487$ & 116,9243 & 3,5925 & 5,7390 & $-0,2162$ \\
6 & 0,9107 & $-3,5581$ & 122,2922 & 4,8035 & 2,4830 & $-0,2411$ \\
7 & 2,5814 & $-2,4106$ & 40,6127 & 3,0607 & 4,1717 & $-0,1859$ \\
8 & 0,4863 & $-1,1013$ & 74,2200 & 0,6586 & 2,1939 & $-0,2360$ \\
9 & 4,6257 & 0,8367 & 118,5494 & $-0,1708$ & 6,9254 & $-0,6574$ \\
10 & 2,0116 & 1,4757 & 124,0546 & $-1,3339$ & 3,7206 & $-0,4856$ \\
11 & 2,4538 & 1,3937 & 40,1616 & $-1,2230$ & 5,3479 & $-0,3981$ \\
12 & 1,9333 & 2,4104 & 70,0864 & $-3,4968$ & 3,4432 & $-0,7438$ \\
13 & 7,1664 & $-3,1540$ & 103,0038 & 4,0342 & 9,4541 & 0,9492 \\
14 & 4,4556 & $-2,8468$ & 151,3339 & 4,7214 & 7,8099 & 0,8530 \\
15 & 17,4755 & $-1,3017$ & 126,0024 & 1,7116 & 7,8584 & 0,5139 \\
16 & 4,8889 & $-1,0323$ & 79,6078 & $-0,0994$ & 7,4749 & 1,2171 \\
17 & 1,3263 & $-0,9223$ & 33,2926 & 1,4628 & 4,4863 & 1,8357 \\
18 & 1,7431 & $-2,0065$ & 55,5718 & 1,5936 & 3,6720 & 1,2091 \\
19 & 40,0016 & $-1,0887$ & 106,3161 & 1,4113 & 4,0584 & 1,6081 \\
20 & $-0,0226$ & 2,0655 & 43,3952 & $-1,3455$ & 2,4500 & 2,0017 \\
\hline
\end{tabular}

Perhitungan tegangan diperlukan untuk menentukan gaya pada tiap kolom akibat dari beban struktur bangunan. Hasil dari perhitungan tegangan seperti pada Tabel 5. 
Tabel 5. Hasil perhitungan tegangan maksimum dan tegangan minimum

\begin{tabular}{ccccccc}
\hline Titik & $\sigma_{1}\left(\mathrm{kN} / \mathrm{m}^{2}\right)$ & $\sigma_{2}\left(\mathrm{kN} / \mathrm{m}^{2}\right)$ & $\sigma_{3}\left(\mathrm{kN} / \mathrm{m}^{2}\right)$ & $\sigma_{4}\left(\mathrm{kN} / \mathrm{m}^{2}\right)$ & $\sigma_{\text {maks }}\left(\mathrm{kN} / \mathrm{m}^{2}\right)$ & $\sigma_{\min }\left(\mathrm{kN} / \mathrm{m}^{2}\right)$ \\
\hline 1 & 69,5251 & 38,3368 & 90,6653 & 59,4770 & 90,6653 & 38,3368 \\
2 & 96,2767 & 79,9862 & 128,1405 & 111,85 & 128,1405 & 79,9862 \\
3 & 76,1101 & 53,5409 & 99,6662 & 77,0970 & 99,6662 & 53,5409 \\
4 & 34,5225 & 27,4240 & 76,4320 & 69,3335 & 76,4320 & 27,4240 \\
5 & 125,2252 & 79,9432 & 96,8798 & 51,5979 & 125,2252 & 51,5979 \\
6 & 121,2163 & 101,6249 & 83,3160 & 63,7246 & 121,2163 & 63,7246 \\
7 & 59,2416 & 26,3257 & 35,0922 & 2,17643 & 59,2416 & 2,17643 \\
8 & 67,3744 & 50,0641 & 62,1778 & 44,8675 & 67,3744 & 44,8675 \\
9 & 116,288 & 61,6449 & 117,6357 & 62,9927 & 117,6357 & 61,6449 \\
10 & 103,2189 & 73,8626 & 113,7436 & 84,3873 & 113,7436 & 73,8626 \\
11 & 46,6407 & 4,4450 & 56,2907 & 14,0950 & 56,2907 & 4,44509 \\
12 & 52,7838 & 25,6166 & 80,3741 & 53,2069 & 80,3741 & 25,6166 \\
13 & 131,0984 & 56,5035 & 99,2677 & 24,6729 & 131,0984 & 24,6729 \\
14 & 163,8673 & 102,246 & 126,6143 & 64,9929 & 163,8673 & 64,9929 \\
15 & 133,0306 & 71,0259 & 119,5258 & 57,5211 & 133,0306 & 57,5211 \\
16 & 89,2922 & 30,3135 & 90,0763 & 31,0976 & 90,0763 & 30,3135 \\
17 & 48,6436 & 13,2462 & 37,1017 & 1,7043 & 48,6436 & 1,70433 \\
18 & 62,7933 & 33,8208 & 50,2197 & 21,2472 & 62,7933 & 21,2472 \\
19 & 101,9686 & 69,9469 & 90,8335 & 58,8118 & 101,9686 & 58,8118 \\
20 & 37,1703 & 17,8397 & 47,7862 & 28,4556 & 47,7862 & 17,8397 \\
\hline
\end{tabular}

Berdasarkan nilai tegangan dari setiap titik fondasi yang telah dihitung, dapat dilihat bahwa nilai $\sigma$ maksimum ada pada titik fondasi nomor 14 dengan nilai tegangan $163,8673 \mathrm{kN} / \mathrm{m}^{2}$.

Perhitungan daya dukung fondasi sangat diperlukan untuk mengetahui kekuatan fondasi. Pada perhitungan daya dukung fondasi dangkal ini dapat dilakukan dengan beberapa metode yaitu Terzaghi, Meyerhof, dan N-SPT. Untuk dimensi fondasi yang digunakan yaitu dengan kedalaman fondasi 1 meter dan lebar 1,15 meter. Hasil perbandingan daya dukung fondasi dapat dilihat pada Tabel 6.

Tabel 6. Hasil perbandingan daya dukung fondasi

\begin{tabular}{cccc}
\hline Daya dukung & Terzaghi & Meyerhof & N-SPT \\
\hline qult $\left(\mathrm{kN} / \mathrm{m}^{2}\right)$ & 543,852 & 605,103 & 506,462 \\
qall $\left(\mathrm{kN} / \mathrm{m}^{2}\right)$ & 181,284 & 201,701 & 168,821 \\
\hline
\end{tabular}

Berdasarkan hasil perhitungan daya dukung fondasi dengan beberapa metode, dapat dilihat bahwa nilai daya dukung terkecil yaitu metode N-SPT. Nilai daya dukung fondasi metode N-SPT diperoleh hasil qall sebesar 168,821 kN/m² yang dimana lebih besar daripada nilai $\sigma$ maksimum yaitu sebesar 163,8673 kN/m².

Penurunan total merupakan perhitungan jumlah dari tiga komponen penurunan yaitu penurunan segera, penurunan konsolidasi primer, dan penurunan konsolidasi sekunder. Sehingga diperoleh penurunan total seperti pada Tabel 7. 
Tabel 7. Hasil penurunan total

\begin{tabular}{cccccccc}
\hline Titik & $\mathrm{S}_{\mathrm{e} \min }(\mathrm{cm})$ & $\mathrm{S}_{\mathrm{e} \text { maks }}(\mathrm{cm})$ & $\mathrm{S}_{\mathrm{c} \mathrm{min}}(\mathrm{cm})$ & $\mathrm{S}_{\mathrm{c} \text { maks }}(\mathrm{cm})$ & $\mathrm{S}_{\mathrm{s}}(\mathrm{cm})$ & $\mathrm{S}_{\mathrm{t} \text { min }}(\mathrm{cm})$ & $\mathrm{S}_{\mathrm{t} \text { maks }}(\mathrm{cm})$ \\
\hline 1 & 0,2910 & 0,5197 & 5,3489 & 8,5177 & 2,0026 & 7,6426 & 11,0399 \\
2 & 0,5488 & 0,7592 & 8,1318 & 10,5588 & 2,0026 & 10,6832 & 13,3206 \\
3 & 0,3807 & 0,5822 & 6,3809 & 9,0768 & 2,0026 & 8,7642 & 11,6616 \\
4 & 0,2193 & 0,4334 & 4,2385 & 7,6470 & 2,0026 & 6,4604 & 10,0830 \\
5 & 0,3948 & 0,7165 & 6,3690 & 10,2734 & 2,0026 & 8,7663 & 12,9924 \\
6 & 0,4555 & 0,7067 & 7,1518 & 10,1629 & 2,0026 & 9,6099 & 12,8722 \\
7 & 0,0683 & 0,3176 & 1,9378 & 6,3914 & 2,0026 & 4,0087 & 8,7117 \\
8 & 0,3035 & 0,4019 & 5,5950 & 7,1945 & 2,0026 & 7,9011 & 9,5990 \\
9 & 0,4410 & 0,6857 & 7,0037 & 9,9888 & 2,0026 & 9,4474 & 12,6770 \\
10 & 0,5024 & 0,6766 & 7,7224 & 9,8776 & 2,0026 & 10,2274 & 12,5569 \\
11 & 0,0776 & 0,3041 & 2,1730 & 6,1997 & 2,0026 & 4,2532 & 8,5064 \\
12 & 0,2134 & 0,4527 & 4,1314 & 7,8676 & 2,0026 & 6,3474 & 10,3228 \\
13 & 0,2570 & 0,7220 & 4,3177 & 10,3777 & 2,0026 & 6,5773 & 13,1023 \\
14 & 0,5031 & 0,9351 & 7,4301 & 11,9079 & 2,0026 & 9,9358 & 14,8456 \\
15 & 0,4338 & 0,7637 & 6,8095 & 10,6442 & 2,0026 & 9,2459 & 13,4105 \\
16 & 0,2477 & 0,5088 & 4,5038 & 8,4384 & 2,0026 & 6,7541 & 10,9498 \\
17 & 0,0557 & 0,2607 & 1,8273 & 5,6202 & 2,0026 & 3,8855 & 7,8835 \\
18 & 0,1733 & 0,3548 & 3,7189 & 6,7511 & 2,0026 & 5,8948 & 9,1085 \\
19 & 0,4109 & 0,5995 & 6,7460 & 9,2233 & 2,0026 & 9,1595 & 11,8253 \\
20 & 0,1408 & 0,2716 & 3,3726 & 5,6572 & 2,0026 & 5,5160 & 7,9315 \\
\hline
\end{tabular}

Berdasarkan hasil penurunan total yang diperoleh, dapat dilihat bahwa penurunan total pada titik fondasi nomor 14 merupakan penurunan terbesar yaitu sebesar 14,8456 cm yang dimana masih di bawah batas penurunan maksimal yaitu $15 \mathrm{~cm}$.

Untuk menenutukan nilai faktor keamanan suatu kestabilan lereng, digunakan aplikasi kesetimbangan batas. Perhitungan kestabilan lereng yang digunakan adalah metode bishop. Sedangkan untuk beban rumah tinggal 2 lantai dibuat dalam beban merata dari total beban bangunan dibagi dengan luasan bangunan, sehingga diperoleh beban merata sebesar $21 \mathrm{kN} / \mathrm{m}^{2}$. Model lereng sebelum hujan dengan MAT tanah berada pada kedalaman 9 m dapat dilihat pada Gambar 6.

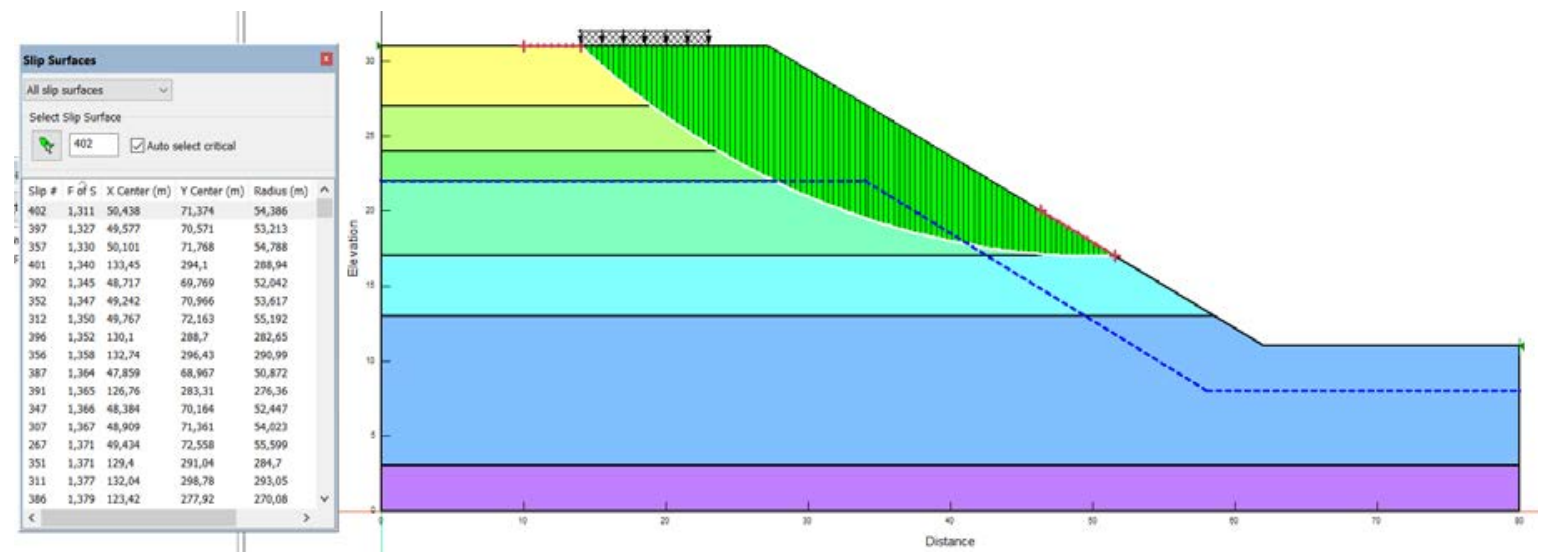

Gambar 6. Hasil analisis kestabilan lereng kedalaman MAT 9 m

Dapat dilihat pada Gambar 6 yang berisikan tabel faktor keamanan diperoleh nilai FK sebesar 1,311 yang dimana nilai FK lebih dari 1,25. Sehingga berdasarkan dari Tabel 1 lereng termasuk dalam kategori lereng relatif stabil. Selanjutnya membuat model lereng dengan menaikan MAT akibat dari hujan yang berlangsung lama, hal ini mengakibatkan perubahan faktor keamanan pada lereng. 


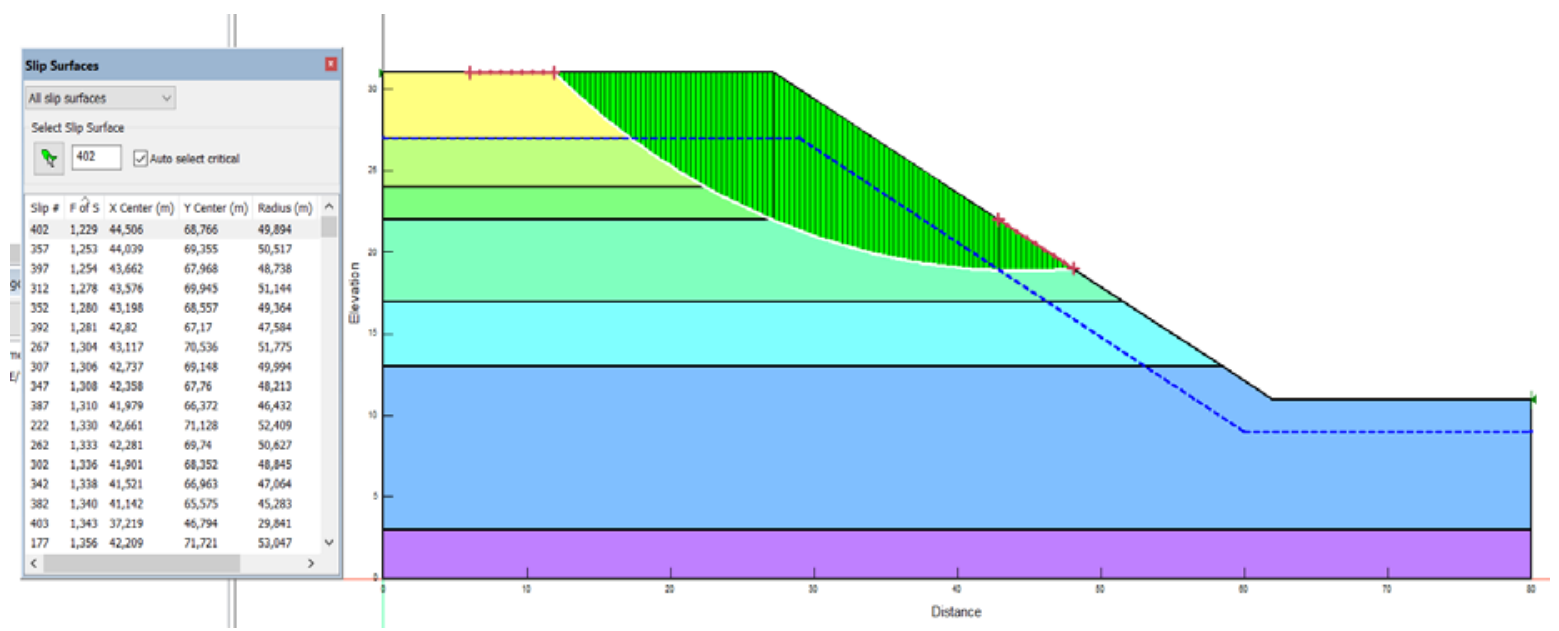

Gambar 7. Hasil analisis kestabilan lereng kedalaman MAT 4 m tanpa adanya beban luar

Dapat dilihat pada Gambar 7 yang berisikan tabel faktor keamanan diperoleh nilai FK sebesar 1,229 yang dimana faktor keamanan kurang dari 1,25. Sehingga berdasarkan dari Tabel 1 lereng termasuk dalam kategori longsor pernah terjadi (lereng kritis). Sedangkan untuk model lereng setelah kenaikan MAT dengan adanya beban rumah tinggal 2 lantai dapat dilihat pada Gambar 8.

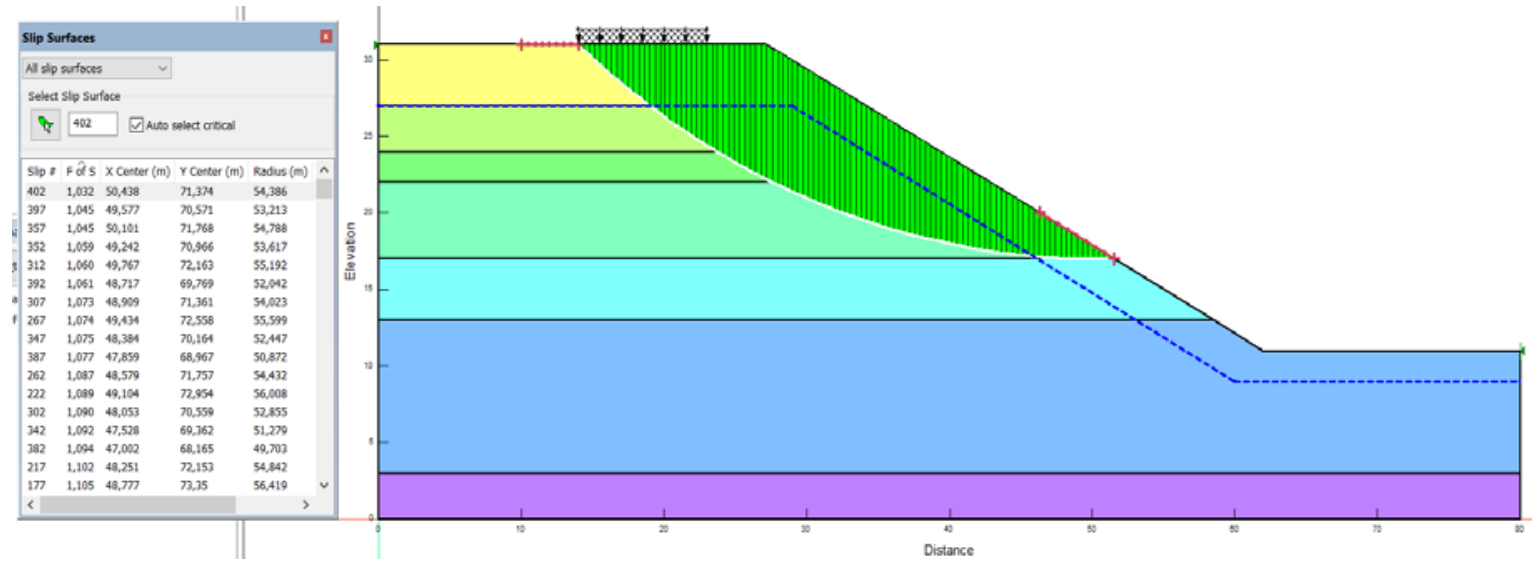

Gambar 8. Hasil analisis kestabilan lereng kedalaman MAT 4 m

Berdasarkan gambar di atas yang berisikan tabel faktor keamanan diperoleh nilai FK lebih kecil yaitu 1,032 yang dimana faktor keamanan kurang dari 1,07. Sehingga lereng termasuk dalam kategori longsor biasa/sering terjadi. Tabel nilai faktor keamanan kestabilan lereng MAT naik tiap 1 meter disajikan pada Tabel 8 dan grafik kestabilan lereng pada Gambar 9.

Tabel 8. Hasil faktor keamanan kestabilan lereng

\begin{tabular}{cc}
\hline Keterangan & Faktor keamanan \\
\hline Sebelum hujan (MAT -9 m) & 1,311 \\
Setelah hujan (MAT -8 m) & 1,194 \\
Setelah hujan (MAT -7 m) & 1,135 \\
Setelah hujan (MAT -6 m) & 1,098 \\
Setelah hujan (MAT -5 m) & 1,063 \\
Setelah hujan (MAT -4 m) & 1,032 \\
\hline
\end{tabular}




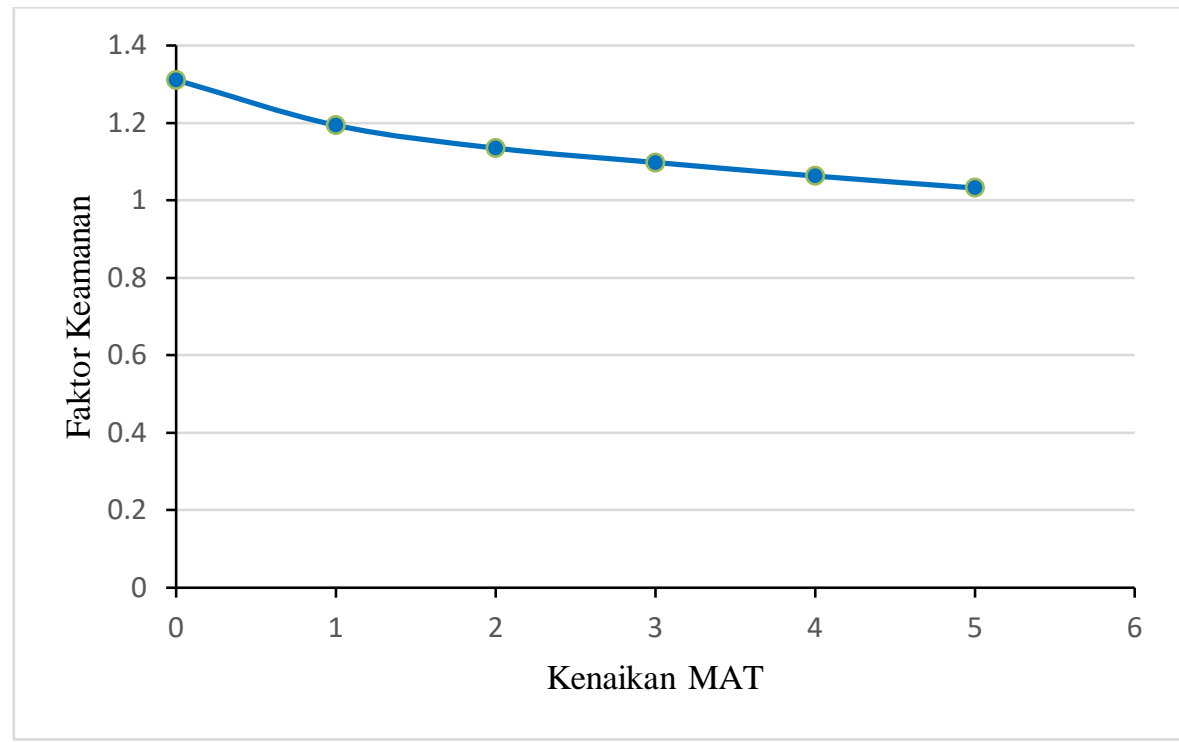

Gambar 9. Hubungan kenaikan MAT dengan faktor keamanan

Berdasarkan hasil grafik hubungan kenaikan MAT dengan faktor keamanan dapat dilihat bahwa semakin naik MAT maka nilai faktor keamanan yang diperoleh semakin kecil.

\section{KESIMPULAN DAN SARAN}

\section{Kesimpulan}

Berdasarkan hasil penelitian dan analisis yang dilakukan dapat disimpulkan bahwa:

1. Daya dukung fondasi berdasarkan perhitungan dengan beberapa metode diperoleh nilai yang terkecil yaitu dari N-SPT sebesar 168,821 kN/m².

2. Daya dukung fondasi lebih besar daripada tegangan maksimum $\left(168,821 \mathrm{kN} / \mathrm{m}^{2}>163,8673 \mathrm{kN} / \mathrm{m}^{2}\right)$, sehingga fondasi mampu menahan gaya dari struktur bangunan.

3. Berdasarkan perhitungan penurunan total diperoleh penurunan terbesar pada titik fondasi nomor 14 yaitu sebesar $14,8456 \mathrm{~cm}$.

4. Nilai faktor keamanan yang diperoleh dengan menggunakan aplikasi kesetimbangan batas sebelum hujan sebesar 1,311 sedangkan faktor keamanan setelah mengalami kenaikan MAT 5 meter sebesar 1,032.

5. Berdasarkan nilai faktor keamanan setelah mengalami kenaikan MAT yang diperoleh kurang dari 1,25. Sehingga lereng masuk dalam kategori longsor biasa/sering terjadi.

\section{Saran}

Berdasarkan hasil penelitian dan analisis yang dilakukan, penulis memberikan beberapa saran yaitu:

1. Pada perhitungan lebih baik menggunakan data tanah hasil uji laboratorium dibandingkan dengan menggunakan data tanah hasil korelasi.

2. Faktor keamanan kestabilan lereng menggunakan lebih dari 1 metode, sehingga hasil dari faktor keamanan dapat dibandingkan dengan metode lain.

\section{DAFTAR PUSTAKA}

Badan Standarisasi Nasional. (2017). SNI 8460:2017 Persyaratan Perancangan Geoteknik. Jakarta.

Bowles, J. E. (1992). Sifat-sifat Fisis dan Geoteknik Tanah. Jakarta: Penerbit Erlangga.

Idris, M. (2021, January 22). Jumlah Penduduk Indonesia Terkini Mencapai 271,34 Juta. Retrieved from Kompas: https://money.kompas.com/read/2021/01/22/090554926/jumlah-penduduk-indonesia-terkini-mencapai27134-juta?page=all

Janbu, N., Bjerrum, \& Kjalrnsli. (1956). Soil Mechanics Applied to some Enginering Problems. Norwegian: N.G.I. Publication.

Margaretha, V. G., Turangan, P. A., \& Sompie, O. (2014). Analisa Kestablian Lereng Dengan Metode Fellenius. Jurnal Sipil Statik. 
Putra, C. E., \& Makarim, C. A. (2020). Analisis Alternatif Perbaikan Tanah Lunak dan Sangat Lunak Pada Jalan Tol. Jurnal Mitra Teknik Sipil.

Soepratohardjo. (1976). Jenis Tanah di Indonesia, Seri 3 C. Bogor: Lembaga Penelitian Tanah.

Terzaghi, K., \& Peck, R. (1943). Theoritical Soil Mechanic. New York: John Willey \& Sons. 
Analisis Model Kegagalan Konstruksi Rumah Tinggal 2

Jeffri Ardianto, et al.

Lantai akibat Rangkak di Bawah Lereng Timbunan 